\title{
Strategi Pemasaran Museum Buleleng Dalam Upaya Meningkatkan Jumlah Kunjungan Wisatawan
}

\author{
I Gede Putra Nugraha ${ }^{(1)}$ \\ Made Dian Putri Agustina ${ }^{(2)}$ \\ ${ }^{(1)}$ Program Studi Perhotelan, Universitas Pendidikan Ganesha \\ ${ }^{(2)}$ Program Studi Manajemen, Universitas Hindu Indonesia \\ e-mail: dedenugraha@ymail.com
}

\begin{tabular}{|l|l|l}
\hline Diterima: 10 Mei 2020 & Direvisi: 22 Juli 2020 & Disetujui: 30 Juli 2020
\end{tabular}

\begin{abstract}
This study aims to describe the decrease factor of tourist visits to the Museum Buleleng, marketing strategies used to increase the number of tourist visits to the Museum Buleleng. This study used a SWOT analysis to identify strengths, weaknesses, opportunities, and threats in Buleleng Museum, and discussed using qualitative descriptive analysis. This research subject is the manager of the Buleleng Museum. Then the object of this study is data on the number of tourists. Data on the number of tourist arrivals was obtained through interviews with related parties. Data were analyzed descriptively. These results indicate that, factors causing the decline in the number of tourist visits to the Museum Buleleng namely internal factors and external factors, do not Buleleng Museum marketing strategy, which is due to funding constraints. Results of the analysis of the data showed that important to know the potential, weaknesses that should be corrected, an opportunity that must be exploited to the maximum, and a threat to be faced so that it can be known from the marketing strategy to be followed.
\end{abstract}

Keyword : Strategy, Marketing, Museum, Tourist

\section{Pendahuluan}

Museum di negara Indonesia telah ada sejak tahun 1862, yang didirikan oleh pemerintah India Belanda, di Jakarta. Tidak hanya di Jakarta, Bali Utara juga memiliki museum yang menyimpan benda-benda peninggalan sejarah, yang menceritakan tentang aktivitas-aktivitas masyarakat pada zaman lampau. Museum tersebut dikenal dengan sebutan "Museum Buleleng" yang terletak di lingkungan Puri Sasana Budaya Singaraja. Berawal dari pengajuan sebuah proposal kepada Drs. Ketut Wiratha Sindu (Bupati Buleleng) pada tahun 1994 untuk membangun sebuah museum di Bali Utara yang akan difungsikan sebagai media penyimpanan benda-benda bernilai sejarah. 
Hingga pada tahun 1997 museum didirikan di bawah pengelolaan Dinas Pendidikan yang diberi nama "Kesari Rama", tidak lama beroperasi terjadi sebuah konflik politik di Bali Utara yang menyebabkan kerugian besar, terjadinya kehancuran ditiap gedung pemerintahan yang menyebabkan Museum Kesari Rama terpaksa ditutup, dan koleksi-koleksi museum yang tersisa dipindahkan ke Museum di Bali Selatan. Kejadian tersebut tidak menyurutkan semangat para pencetus pendiri Museum Buleleng pudar, lima tahun kemudian Museum Buleleng diambil alih pengelolaanya oleh Drs. Ketut Wiratha Sindu dan berganti nama menjadi "Etno Grafis" tepat pada tanggal 30 Maret 2002 (Drs. I Wayan Santika, S.Pd., B.Sc, Anggota Yayasan Pelestarian Warisan Budaya).

Salah satu media cetak (Antara News, 2012) menyatakan bahwa "Museum Buleleng mengalami kebangkrutan, sejumlah pengurus Yayasan Pelestarian Warisan Bali Utara sempat melakukan konsultasi terkait kesulitan yang dihadapi tersebut. Pemerintah Kabupaten Buleleng untuk pengelolaan museum mengucurkan dana sangat kecil sehingga tidak bisa melakukan perawatan benda-benda budaya dengan baik. Jika kondisi itu masih berlanjut di masa-masa mendatang dikhawatirkan pihak Yayasan akan menutup kegiatan Museum Buleleng”. Berikut ini data tingkat kunjungan wisatawan ke daya tarik wisata Museum Buleleng:

Tabel 1.1 Jumlah Kunjungan Wisatawan ke Museum Buleleng

\section{Jumlah Wisatawan}

\begin{tabular}{cccc}
\hline Tahun & $\begin{array}{c}\text { Wisatawan } \\
\text { Domestik }\end{array}$ & $\begin{array}{c}\text { Wisatawan } \\
\text { Asing }\end{array}$ & $\begin{array}{c}\text { Jumlah } \\
\text { Keseluruhan }\end{array}$ \\
\hline 2015 & 940 & 2.664 & 3.604 \\
2016 & 604 & 1.046 & 1.650 \\
2017 & 683 & 879 & 1.543 \\
2018 & 664 & 502 & 1.166 \\
2019 & 610 & 758 & 1.368 \\
\hline
\end{tabular}

Sumber: Pengelola Museum Buleleng (2019)

Dari uraian permasalahan di atas maka melakukan penelitian dengan judul "Strategi Pemasaran Museum Buleleng Dalam Upaya Meningkatkan Jumlah Kunjungan Wisatawan” dirasa bermanfaat guna memecahkan masalah yang terjadi.

\section{Telaah Literatur dan Kajian Pustaka}

Sumarmi dan Soeprihanto (2010:274) menjelaskan, "Marketing mix adalah kombinasi dari variabel atau kegiatan yang merupakan inti dari sistem pemasaran yaitu produk, harga, promosi, dan distribusi. Dengan kata lain marketing mix adalah kumpulan dari variabel yang dapat digunakan oleh perusahaan untuk dapat mempengaruhi tanggapan konsumen”. 


\section{Product (Produk)}

Menurut Sumarni dan Soeprihanto (2010:274), "Produk adalah setiap apa saja yang bisa ditawarkan di pasar untuk mendapatkan perhatian, permintaan, pemakaian atau konsumsi yang dapat memenuhi keinginan atau kebutuhan".

2. Price (Harga)

Menurut Sumarni dan Soeprihanto (2010:281) harga adalah, "Jumlah uang (ditambah beberapa produk kalau mungkin) yang dibutuhkan untuk mendapatkan sejumlah kombinasi dari barang beserta pelayanannya".

\section{Place (Tempat)}

Tempat dalam marketing mix biasa disebut dengan saluran distribusi, saluran dimana produk tersebut sampai kepada konsumen. Definisi dari Sumarni dan Soeprihanto (2010:288) tentang saluran distribusi adalah, "Saluran yang digunakan oleh produsen untuk menyalurkan produk tersebut dari produsen sampai ke konsumen atau industri pemakai"

\section{Promotion (Promosi)}

Menurut Tjiptono (2008:219), pada hakikatnya promosi adalah suatu bentuk komunikasi pemasaran. Yang dimaksud dengan komunikasi pemasaran adalah aktivitas pemasaran yang berusaha menyebarkan informasi, mempengaruhi/membujuk, atau mengingatkan pasar sasaran atas perusahaan dan produknya agar bersedia menerima, membeli, dan loyal pada produk yang ditawarkan perusahaan yang bersangkutan.

Salah satu alat pelengkap penting dikenal sebagai model 4A pemasaran. Model 4A dikembangkan oleh Jagdish Sheth, seorang profesor pemasaran di Emory University, dan Dr Rajendra Sisodia, seorang profesor pemasaran di Bentley University.

a. Penerimaan (Acceptability)

Penerimaan dari model 4A menjelaskan bahwa produk atau layanan yang ditawarkan harus memenuhi atau melebihi kebutuhan dan harapan pelanggan pada target pasar tertentu. terdapat dua dimensi penerimaan - penerimaan fungsional dan penerimaan psikologis.

b. Keterjangkauan (Affordability)

Mengacu pada apakah pelanggan yang dituju secara ekonomi mampu dan psikologis bersedia membayar harga suatu produk . Dalam definisi ini menunjukkan, keterjangkauan juga memiliki dua dimensi - keterjangkauan ekonomi dan keterjangkauan psikologis .

c. Kesadaran (Awareness)

Komponen terakhir dari model 4A adalah kesadaran, yang mengacu pada apakah pelanggan mendapatkan cukup informasi tentang atribut produk dan manfaat dengan cara yang membujuk 
calon pembeli untuk memberikan produk mencoba dan mengingatkan pengguna yang ada mengapa mereka harus terus membeli produk. Dua dimensi kesadaran adalah pengetahuan produk dan brand awareness. Ide dasar di sini adalah bahwa sebagian besar pelanggan potensial tidak akan membeli kecuali mereka memiliki persepsi positif dari merek dan informasi yang memadai mengenai produk atau jasa tertentu.

\section{Metode Penelitian}

Analisis SWOT adalah metode perencanaan strategis yang digunakan untuk mengevaluasi kekuatan (strengths), kelemahan (weaknesses), peluang (opportunities), dan ancaman (threats) dalam suatu proyek atau suatu spekulasi bisnis. Proses ini melibatkan penentuan tujuan yang spesifik dari spekulasi bisnis atau proyek dan mengidentifikasi faktor internal dan eksternal yang mendukung dan yang tidak dalam mencapai tujuan tersebut.

\section{Hasil Penelitian dan Pembahasan}

\section{Faktor Penyebab Penurunan Jumlah Kunjungan Wisatawan Ke Museum Buleleng}

Jika dilihat dari hasil penelitian, faktor penyebab penurunan jumlah kunjungan wisatawan ke Museum Buleleng dapat dibagi menjadi 2, yaitu :

a. Faktor Internal, yang dimana faktor ini terdiri dari poin-poin 4P, yaitu :

1. Produk (product)

- Something to see

Ada beberapa koleksi yang dipamerkan di Museum Buleleng, yang keberadaannya diharapkan untuk mengedukasi para pengunjung. Sehingga dalam poin ini Museum Buleleng sudah terbilang baik.

- Something to do

Pengunjung dapat melakukan penelitian di Museum Buleleng, selain untuk tempat bersenang-senang, tempat wisata diharapkan dapat menawarkan sebuah produk yang dimana para pengunjung dapat terlibat di dalamnya. Dalam unsur ini pihak pengelola juga dapat menambahkan kegiatan menonton film dokumenter bersama.

- Something to buy

Untuk pengunjung di Museum Buleleng belum dapat melakukan aktivitas berbelanja di area Museum Buleleng, dikarenakan disekitar areal belum ada yang berjualan. Pihak pengelola sebaiknya mulai memikirkan unsur ini, agar produk yang ditawarkan di Museum Buleleng terbilang baik untuk dikunjungi oleh wisatawan.

2. Harga (price) 
Salah satu kendala besar yang dihadapi pihak pengelola Museum Buleleng adalah dana, hal tersebut terjadi dikarenakan pihak pengelola tidak menjalin kerjasama yang baik dengan pemerintah terkait. Akan terasa mudah jika pihak pengelola membuat kesepakatan yang baik dengan pemerintah, sehingga pihak pengelola tidak merasa kesulitan dalam mendapatkan izin penerbitan tiket kunjungan wisatawan ke Museum Buleleng. Selain dari hasil tiket kunjungan yang didapat, pihak pengelola pastinya akan mendapat dana tambahan dari pemerintah terkait dalam pembiayaan kegiatan operasional di Museum Buleleng, karena jika hanya mengandalkan kotak donasi sukarela dari para pengunjung, bukan hal yang mustahil jika kedepannya Museum Buleleng akan mengalami kebangkrutan.

Jika dilihat dari hasil penelitian, yang dimana pihak pengelola tidak memiliki harga pasti untuk membayarkan produk yang ditawarkan serta pelayanannya, hal ini dapat dikatagorikan sebagai kelemahan dari pihak pengelola Museum Buleleng.

\section{Tempat (place)}

Dalam hal ini, Museum Buleleng telah memiliki nilai tambah karena Museum Buleleng berlokasi di pusat kota dekat dengan beberapa kantor pemerintahan sehingga secara otomatis untuk poin aksesibilitas mudah dilalui, hanya saja Museum Buleleng tidak memiliki rambu-rambu yang menuju ke arahnya. Akan lebih baik jika ada papan penunjuk ke tujuan wisata, sehingga para wisatawan yang tanpa rencana melintas di areal tersebut dapat mengetahui keberadaan Museum Buleleng, dan juga pencahayaan di dalam Museum akan lebih baik jika ditambah, agar koleksi yang dipamerkan di Museum Buleleng dapat terlihat lebih indah.

Lokasi Museum Buleleng merupakan salah satu keunggulan yang dapat dimanfaatkan oleh pihak pengelola guna menarik kunjungan wisatawan baik wisatawan asing, maupun wisatawan domestik agar tingkat kunjungan lebih meningkat.

\section{Promosi (promotion)}

Promosi yang hanya dilakukan oleh pemerintah untuk Museum Buleleng belum cukup untuk meningkatkan jumlah kunjungan wisatawan. Pihak pengelola Museum Buleleng, harus mengusahakan berbagai cara agar terjalin kerjasama yang baik dengan pemerintah terkait, agar tidak mengalami kendala dana dalam mewujudkan kegiatan ini. Awal tahun 2016 merupakan awal yang baik dalam menjalankan kegiatan promosi ini. Tidak hanya melalui brosur ataupun media elektronik, pihak pengelola Museum Buleleng sebaiknya menjalin kerjasama dengan pihak lain, seperti Travel Agent. Hal ini pastinya akan berdampak baik bagi tingkat kunjungan wisatawan di tahun berikutnya. 
b. Faktor Eksternal, yang dimana faktor ini terdiri dari poin-poin 4A, yaitu :

1. Penerimaan (Acceptability)

Dalam poin ini, respon pengunjung yang harus diperhatikan. Dari hasil penelitian dan wawancara ditemukan beberapa pengunjung yang merasa kecewa karena koleksi yang ditawarkan tidak sesuai dengan ekspektasi mereka, walaupun tidak sedikit juga yang merasa puas berkunjung ke Museum Buleleng.

2. Keterjangkauan (Affordability)

Dalam poin ini, Museum Buleleng belum dapat melihat apakah poin ini sudah tercapai secara maksimal atau belum, karena Museum Buleleng belum memiliki tiket kunjungan wisatawan, hanya mengandalkan kotak donasi yang dibayar secara sukarela. Sehingga walaupun pengunjung merasa puas datang ke Museum Buleleng mereka belum tentu membayar kunjungan. Jika hal ini tidak dapat ditangani secara tanggap, maka poin affordability dapat menjadi sebuah ancaman besar.

3. Aksesibilitas (Accessibility)

Aksesibilitas di Museum Buleleng sudah sangat baik, hanya saja perlu ditambahkan papan penunjuk arah menuju Museum Buleleng, agar wisatawan yang tanpa sengaja melintas mengetahui akan keberadaan Museum Buleleng.

\section{Awareness}

Kurang lebih 10 pengunjung yang datang berulang kali, dengan tujuan yang hampir sama yaitu melakukan penelitian di Museum Buleleng, dirasa kurang maksimal dalam poin ini.

\section{Strategi Pemasaran Yang Digunakan Dalam Meningkatkan Jumlah Kunjungan Wisatawan} Ke Museum Buleleng

Strategi pemasaran yang digunakan dalam meningkatkan jumlah kunjungan wisatawan ke Museum Buleleng untuk saat ini belum ada, karena seluruh kegiatan yang berkaitan dengan pemasaran berhenti sejak tahun 2006. Hal ini terjadi dikarenakan kurangnya dana promosi yang dimiliki oleh pihak pengelola. jika kendala ini dapat teratasi strategi pemasaran yang sebaiknya diterapkan dalam meningkatkan jumlah kunjungan wisatawan ke Museum Buleleng yaitu dengan mengkombinasikan antara 4P dan 4A dengan Analisis SWOT, dari sini akan terlihat hal apa yang harus ditingkatkan dan dipertahankan.

\section{Simpulan}

Berdasarkan hasil pembahasan, dapat ditarik dua kesimpulan yaitu :

1. Terdapat dua faktor penyebab penurunan jumlah kunjungan wisatawan ke Museum Buleleng, faktor internal yang meliputi produk dimana wisatawan yang berkunjung ke Museum Buleleng 
belum dapat melakukan aktivitas berbelanja, kemudian price atau harga, dimana Museum Buleleng belum memiliki tiket masuk untuk para pengunjung Museum Buleleng, sehingga dana hanya bersumber dari dana sukarela yang diberikan oleh pengunjung melalui kotak donasi. Place atau tempat yang sudah tertata rapi dan indah, akan tetapi pencahayaan di dalam museum masih kurang maksimal. Promotion atau promosi yang tidak berjalan sejak tahun 2007 dikarenakan kendala dana. Untuk faktor eksternal yang memberi dampak menurunnya tingkat kunjungan wisatawan ke Museum Buleleng, yaitu : acceptability, dimana terdapat beberapa pengunjung yang memberikan respon kurang baik setelah berkunjung ke Museum Buleleng, karena koleksi yang ditawarkan kurang lengkap, affordability tidak dapat diketahui dikarenakan para pengunjung hanya memberikan dana secara sukarela saat berkunjung ke Museum Buleleng, yang dimana sebaiknya Museum Buleleng harus memiliki tiket kunjungan resmi, accessability yang sebenarnya sudah dinilai baik, hanya saja tidak ditemukan sama sekali papan penunjuk arah menuju Museum Buleleng, dan yang terakhir awareness, pengunjung yang datang berulangkali hanya berkisar 10 orang, dan hanya bertujuan untuk melakukan sebuah penelitian semata.

2. Pihak pengelola Museum Buleleng tidak melakukan kegiatan pemasaran sejak tahun 2007 , hal ini dikarenakan kendala dana. Jika kendala utama ini dapat teratasi, strategi pemasaran yang harus dilakukan adalah dengan mengkombinasikan marketing mix dengan analisis SWOT, sehingga pihak pengelola mengetahui apa potensi yang harus dipertahankan, potensi yang harus dikembangkan, dan potensi yang harus diperbaiki. Agar nantinya akan berdampak pada kenaikan tingkat kunjungan wisatawan ke Museum Buleleng.

\section{Daftar Pustaka}

Anantara News. Minggu, 9 September 2012. Museum Buleleng terancam bangkrut. From http://www.antaranews.com/berita/331955/museum-buleleng-terancam-bangkrut. $\underline{\text { Sepetember } 2014}$

Antara, I Komang Pasek. Jumat, 14 Maret 2014. Gerakan Nasional Cinta Museum. Pemerintah Kabupaten Karangasem. From http://www.karangasemkab.go.id/index.php?option=com_content\&view=article\&id=2187: gerakan-nasional-cinta-museum-oleh-i-komang-pasek-antara\&catid=54: artikel\&Itemid=81. 30 September 2014

Bayu, W. Sabtu, 04 Februari 2012. Research Of Bali Hotel And Tourism Development Memuat tema seputar kepariwisataan dan perhotelan yang berhubungan dengan lingkungan, sosial budaya, hukum dan manajemen. Pariwisata Bali dan Global (Bali and Global Tourism). Fromhttp://madebayu.blogspot.com/2012/02/pariwisata-budaya.html. 30 September 2014

Farida Robithoh W\&JokoKumoro, 2012. StrategiPromosiWisataPadaDinasKebudayaan, Pariwisata, Pemuda dan Olah Raga KabupatenTemanggung E-Journal Universitas Negeri Yogyakarta. From journal.student.uny.ac.id/jurnal/artikel/3752/21/409. 30 September 2014 
From http://afandi-unmuhgres.blogspot.com/2013/10/konsep-pengertian-mareketing-mix4p.html. 12 November 2014

From http://id.wikipedia.org/wiki/Strategi. 30 September 2014

From http://kekayaanindonesiaku.blogspot.com/p/wisata-budaya.html. 30 September 2014

From http://library.binus.ac.id/eColls/eThesisdoc/Bab2/2011-2-00956-DI\%20Bab2001.pdf. 30 September 2014

From http://skripsi-manajemen.blogspot.com/2011/02/pengertian-definisi-pemasaran.html. 30 September 2014

From http://tourismeconomic.wordpress.com/2012/10/29/wisata-pariwisata-wisatawankepariwisataan-unsur-unsur-pariwisata/. 12 November 2014

From http://www.pengertianahli.com/2013/12/pengertian-strategi-menurut-para-ahli.html. 30 September 2014

Karta, Ni LuhPutuAgustini, 1 Februari 2014. Strategi Komunikasi Pemasaran Ekowisata Pada Destinasi Wisata Dolphin HuntingLovina. Jurnal Manajemen Strategi Bisnis dan $\begin{array}{llllll}\text { Kewirausahaan } & \text { Vol. } & 8 & \text { No. } & 1 . & \text { From }\end{array}$ ojs.unud.ac.id/index.php/jmbk/article/download/8076/6090. 30 September 2014

Saktiawan, F.Yhani, SP.,M.Si. 12 November 2010. Pentingnya Membangun Partisipasi Masyarakat Dalam Pengembangan Desa Wisata. buletin betung kerihun. From http://buletinbetungkerihun.wordpress.com/. 30 September 2014 